\title{
ГЕОФИЗИЧЕСКИЕ НАБЛЮДЕНИЯ ВО ВРЕМЯ ПРОЛЕТА МЕТЕОРОИДА «ЧЕЛЯБИНСК»
}

\author{
В.С. Селезнев, А.В. Лисейкин, А.А. Еманов, А.Ю. Белинская
}

Геофизическая служба СО РАН, 630090, Новосибирск, просп. Академика Коптюга, 3, Россия

Работа посвящена описанию эффектов пролета метеороида «Челябинск», взорвавшегося 15 февраля 2013 г. над территорией Челябинской области, в геофизических данных, полученных на станциях наблюдений в Западной Сибири. С использованием записей камер видеонаблюдения и автомобильных видеорегистраторов определены траектория и скорость движения метеорного тела с момента начала свечения и до момента разрушения. Используя записи широкополосных сейсмических станций, по временам вступлений поверхностной волны, возникшей в результате взрыва метеороида, определено точное время взрыва - 03:20:34 UTC (всемирное координированное время). По амплитудам поверхностной волны оценена энергия взрыва в предположении, что источник точечный, аналогичный высотному термоядерному взрыву. Она составила около 100 кт в тротиловом эквиваленте. Сформирован архив данных записей сейсмологических станций во время пролета метеороида.

Метеороид «Челябинск», траектория движения метеороида, поверхностные волны, энергия высотного взрыва.

\section{GEOPHYSICAL OBSERVATIONS DURING THE FLIGHT OF THE CHELYABINSK METEOROID}

\section{V.S. Seleznev, A.V. Liseikin, A.A. Emanov, and A.Yu. Belinskaya}

The paper describes the effects of the passage of the Chelyabinsk meteoroid (exploded on 15 February 2013 over the Chelyabinsk Region), which were established from geophysical data from West Siberian stations. The trajectory and speed of the meteoric body from the start of the glow to the breakup were recorded by surveillance cameras and dashcams. Records from broadband seismic stations were used to determine the exact time of the explosion (03:20:34 UTC) from the arrival times of the surface wave produced by this event. The explosion energy was estimated from the surface-wave amplitudes at $\sim 100$ ktons on the assumption that the wave originated from a point source similar to a high-altitude thermonuclear explosion. A database of records from seismic stations obtained during the meteoroid passage has been compiled.

Chelyabinsk meteoroid, meteoroid trajectory, surface waves, energy of high-altitude explosion

\section{ВВЕДЕНИЕ}

15 февраля 2013 г. произошло неординарное событие. Метеороид, пролетевший над территорией Сибири и взорвавшийся в Челябинской области, вызвал огромный интерес в мире. Это обусловлено следующими причинами:

1) крайне редко метеорное тело взрывается в районе крупного населенного пункта;

2) болид был заснят на множество камер видеонаблюдения, автомобильных видеорегистраторов и мобильных телефонов, записи с которых быстро разлетелись по всему миру.

Наше внимание метеороид привлек прежде всего тем, что его траектория проходила недалеко от крупнейшей в Сибири геофизической обсерватории «Ключи» (Новосибирская область). Здесь осуществляется регулярный мониторинг параметров ионосферы, магнитного поля и космических лучей. Кроме того, действует сейсмологическая сеть станций Геофизической службы СО РАН, расположенных в Алтае-Саянском и Байкальском регионах. Такая развитая система наблюдений за геофизическими полями позволила зафиксировать явления, сопровождающие пролет метеороида.

Целью статьи является фиксация эффектов пролета метеороида «Челябинск» и его взрыва в геофизических данных, полученных на станциях наблюдений в Западной Сибири.

\section{РАСЧЕТ ТРАЕКТОРИИ ПРОЛЕТА И СКОРОСТИ БОЛИДА}

Обширный видеоматериал из различных точек наблюдения позволяет с большой точностью определить траекторию полета и скорость болида, используя как расположение видимого следа на кадрах, так и звуки с места его взрыва (таблица). При расчетах мы использовали разность времен между наблюдаемыми эффектами (вспышки от взрывов, звуковые явления, ударная волна) во время пролета болида, так как на видеороликах в большинстве случаев время выставлено без синхронизации с сигналами точного времени. Это вносит разночтение в определение точных моментов событий. 


\begin{tabular}{|c|c|c|c|c|}
\hline \multirow{2}{*}{ Название точки } & с.ш. & в.д. & \multirow{2}{*}{ Ссылка на видео } & \multirow{2}{*}{ Примечания } \\
\hline & \multicolumn{2}{|c|}{ град. } & & \\
\hline $\mathrm{T} 1$ & 54.838807 & 61.005291 & - & Конец свечения \\
\hline $\mathrm{T} 2$ & 54.853240 & 61.521180 & - & Начало взрывов \\
\hline $\mathrm{T} 3$ & 54.884089 & 65.654046 & - & Начало свечения \\
\hline$H=26.5$ км & 54.843837 & 61.400503 & - & Определение высоты \\
\hline г. Курган & 55.442143 & 65.335400 & $\begin{array}{l}\text { http://www.youtube.com/ } \\
\text { watch?v=FAMcMmzIugU }\end{array}$ & Полет \\
\hline г. Шадринск & 56.108054 & 63.657312 & $\begin{array}{l}\text { http://www.youtube.com/ } \\
\text { watch?v=MvEYTwwzB0U }\end{array}$ & $»$ \\
\hline г. Тюмень & 57.146084 & 65.583344 & $\begin{array}{l}\text { http://www.youtube.com/ } \\
\text { watch?v=nFtcfy } 9 \mathrm{kdrM}\end{array}$ & $»$ \\
\hline г. Алга & 49.920020 & 57.334851 & $\begin{array}{l}\text { http://www.youtube.com/ } \\
\text { watch?v=EE_LampPEQg }\end{array}$ & $»$ \\
\hline Рынок в г. Коркино & 54.890935 & 61.399572 & $\begin{array}{l}\text { http://www.youtube.com/ } \\
\text { watch?v=yfEaUT2yr-A }\end{array}$ & $»$ \\
\hline $\begin{array}{l}\text { Площадь Революции, г. Че- } \\
\text { лябинск }\end{array}$ & 55.160187 & 61.402664 & $\begin{array}{l}\text { http://www.youtube.com/ } \\
\text { watch?v=JvEqPjEUNcM }\end{array}$ & $\begin{array}{c}\text { Часть полета, точное вре- } \\
\text { мя на регистраторе }\end{array}$ \\
\hline $\begin{array}{l}\text { Машина у офиса, г. Челя- } \\
\text { бинск }\end{array}$ & 55.150049 & 61.363366 & $\begin{array}{l}\text { http://www.youtube.com/ } \\
\text { watch?v=gQ6Pa5Pv_io }\end{array}$ & - \\
\hline $\begin{array}{l}3 б \text { корпус ЮУрГУ, г. Челя- } \\
\text { бинск }\end{array}$ & 55.158864 & 61.364974 & $\begin{array}{l}\text { http://directpress.ru/v- } \\
\text { rossii/15079-chelyabinskij- } \\
\text { meteorit-video-s-kamer- } \\
\text { nablyudeniya-yuurgu-15-fevralya- } \\
\text { 2013-goda }\end{array}$ & Звук \\
\hline г. Оренбург & 51.712416 & 55.206248 & $\begin{array}{l}\text { http://infonavigator.biz/ru/ } \\
\text { groups/139/news-332.html }\end{array}$ & Полет \\
\hline г. Альметьевск & 54.901363 & 52.249589 & $\begin{array}{l}\text { http://www.youtube.com/ } \\
\text { watch?v=qUOMj1Uc1q8 }\end{array}$ & - \\
\hline г. Копейск & 55.097365 & 61.608469 & $\begin{array}{l}\text { http://www.youtube.com/ } \\
\text { watch?v=0L0-Irkj7-c }\end{array}$ & $\begin{array}{l}\text { Ветер в сторону Челябинс- } \\
\text { ка, оценка времени взрыва }\end{array}$ \\
\hline пос. Роза, Челябинская обл. & 54.905852 & 61.457576 & $\begin{array}{l}\text { http://www.youtube.com/ } \\
\text { watch?v=iMVWECEMKP4 }\end{array}$ & Оценка времени взрыва \\
\hline г. Кустанай & 53.225473 & 63.640199 & $\begin{array}{l}\text { http://www.youtube.com/ } \\
\text { watch?v=RCGUdj8cQ9s }\end{array}$ & - \\
\hline г. Миасс & 54.944242 & 60.055896 & $\begin{array}{l}\text { http://www.youtube.com/ } \\
\text { watch?v=GtBqypYKPrw }\end{array}$ & 一 \\
\hline пос. Первомайский & 54.872644 & 61.200792 & $\begin{array}{l}\text { http://www.youtube.com/ } \\
\text { watch?v=R99zvcrqXo8 }\end{array}$ & Оценка времени взрыва \\
\hline $\begin{array}{l}\text { Просп. Победы, г. Челя- } \\
\text { бинск }\end{array}$ & 55.188575 & 61.360038 & $\begin{array}{l}\text { http://www.youtube.com/ } \\
\text { watch?v=mOfloUg7BF4 }\end{array}$ & $\begin{array}{c}\text { Точное время на регистра- } \\
\text { торе, звук через } 152 \text { с }\end{array}$ \\
\hline
\end{tabular}

Прежде всего мы смогли определить проекцию точки на земную поверхность, где метеороид, войдя в атмосферу, начал светиться. Она была определена по записям, полученным в городах Тюмень, Оренбург, Алга, Шадринск, Миасс, Челябинск и Курган (см. таблицу). По ним было вычислено направление на болид в момент его появления на видеокадрах. По нашим расчетам, метеороид начал светиться в т. Т3 (рис. 1) на высоте 68 км (оценена по углу к горизонту точки начала свечения болида на видеозаписи в г. Курган). Координаты определены по пересечению прямых, проведенных из точек наблюдения в направлении начала свечения. При расчетах мы пренебрегли эффектами преломления в атмосфере.

Проекция на земную поверхность т. Т2 (см. рис. 1), где метеороид начал взрываться, определялась по пересечению двух прямых, проведенных из точек площадь Революции и рынок в направлении максимального свечения. Последнее было определено при покадровом просмотре видеозаписей в этих пунктах (см. таблицу). Момент последней вспышки (т. Т1) зарегистрировала камера наблюдения на площади Революции. Прямая в этом направлении, пересекающаяся с траекторией полета, и тень от столба на площади, позволяют определить координаты проекции и высоту - 21 км. От момента появления свече- 


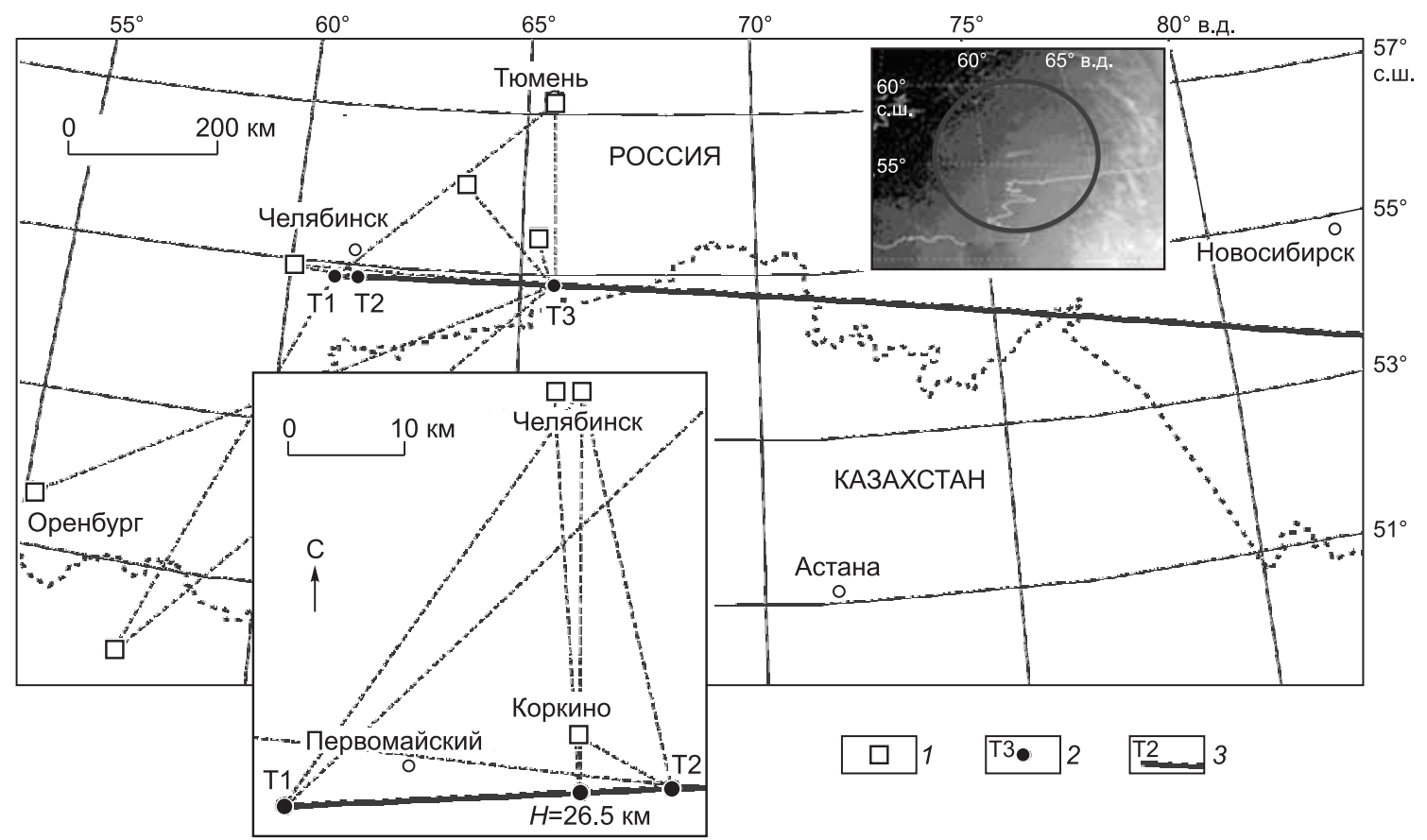

Рис. 1. Проекция траектории движения метеороида с элементами определения.

1 - местоположение видеокамер; 2 - точки траектории, определенные по видеозаписям; 3 - траектория движения.

ния метеороида в небе до последней вспышки прошло 14 с. Скорость метеорного тела на участке от Т2 до Т1 (33.7 км по траектории, время 2.2 с) около 15 км/с, а на участке от Т3 до Т2 (262 км, время 11.8 c) около 22 км/с. Значит в момент, когда метеороид вошел в плотные слои атмосферы, его скорость была не менее $30 \mathrm{\kappa м} / \mathrm{c}$.

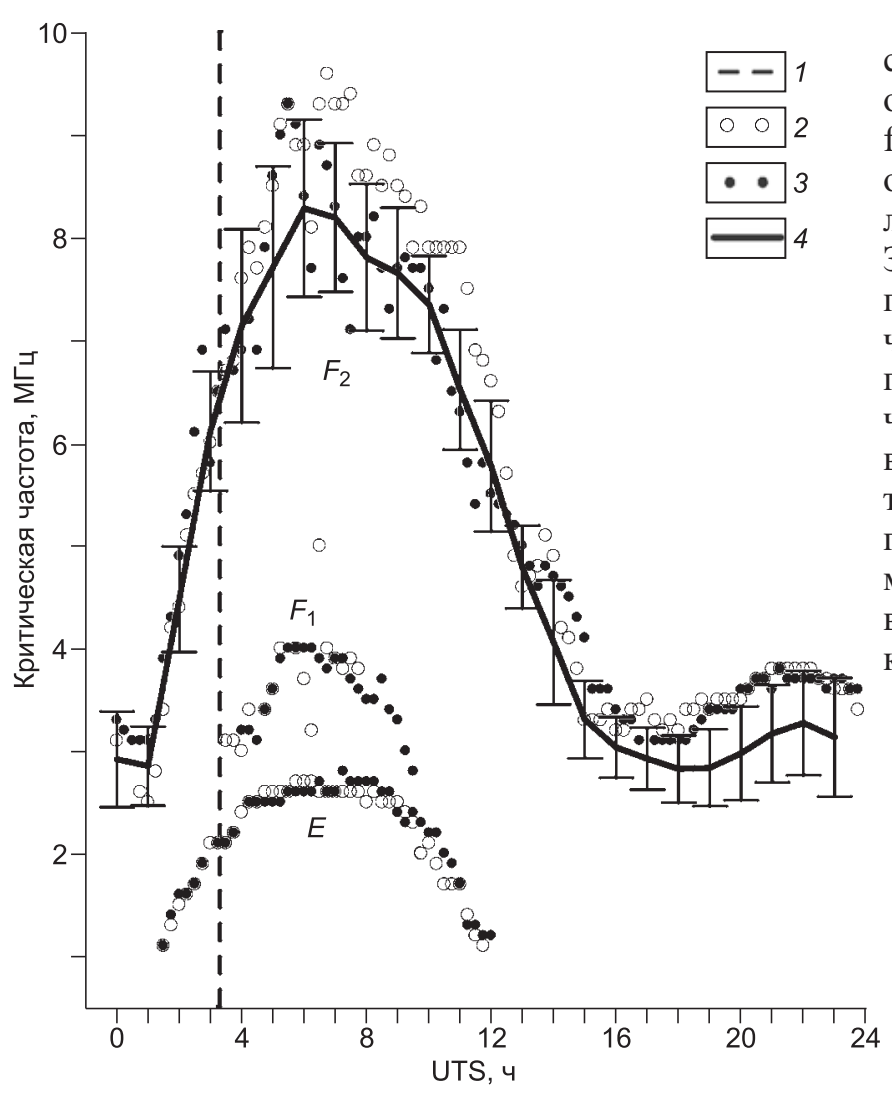

На фотографии (см. рис. 1), сделанной со спутника МЕТ-7, виден конденсационный след от пролета метеороида в атмосфере (http://g1.s3. forblabla.com/u34/photoECA8/20973644132-0/ original.jpeg\#20973644132). Учитывая, что он летел под углом примерно 7-9 ${ }^{\circ}$ к поверхности Земли, проекция его траектории в этом месте параллельна 55-й широте. В предположении, что метеороид до момента разрушения двигался по прямолинейной траектории, нами было вычислено, что он пролетел на 140 км южнее Новосибирска на высоте около 300 км. Это подтверждает и анализ вариаций ионосферных параметров над Новосибирском. После пролета метеорного тела остается ионизованный след на высотах от 100 км и ниже, длиной до нескольких десятков километров с начальным диамет-

Рис. 2. Критические частоты ионосферных слоев $E, F_{1}, F_{2}$ за сутки до и во время пролета метеороида.

1 - момент пролета метеороида; 2, 3 - данные за 14 и 15 февраля 2013 г. соответственно; 4 - среднемесячные значения критической частоты слоя $F_{2}$ со стандартным отклонением. 

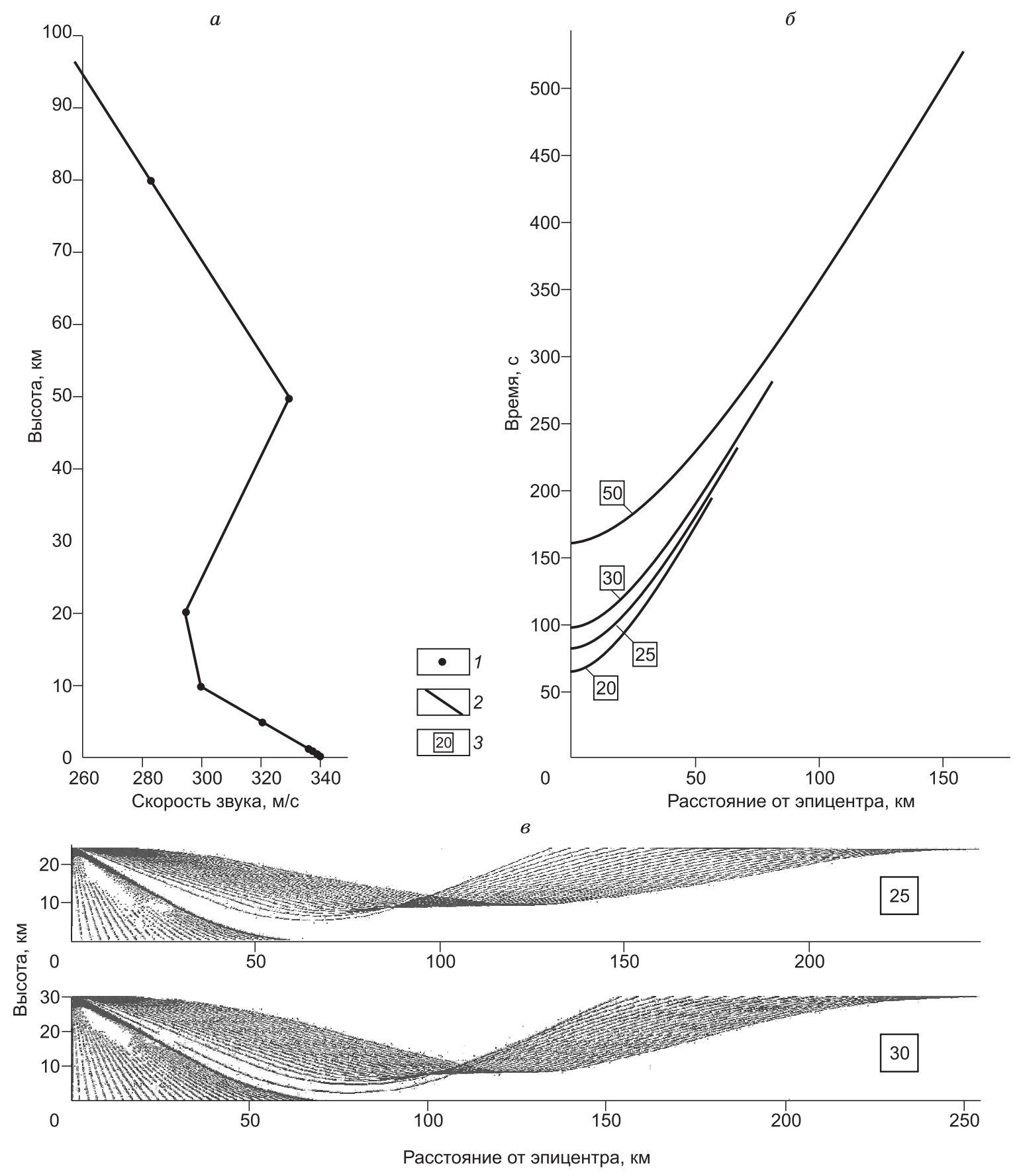

Рис. 3. Расчет параметров распространения звуковых волн в атмосфере от взрыва метеороида.

$a$ - зависимость скорости звука от высоты; $\sigma$ - годографы звуковых волн при различной высоте источника; 8 - траектории лучей при высоте источника 25 и 30 км. 1 - значения по данным [ГОСТ 44-01..., 1981]; 2 - интерполированные значения; 3 - высота источника (км).

ром в несколько метров. Время наблюдения следа - от долей секунды до нескольких минут. Над Новосибирском 15 февраля 2013 г. все характеристики ионосферы были близки к среднемесячным нормам и возмущений не было выявлено (рис. 2).

\section{ЗВУКОВЫЕ ВОЛНЫ}

Для нас особый интерес представляет отрезок траектории от т. Т1 до т. Т2. Пролетая именно этот участок пути, болид и/или его осколки взрывались, причем несколько раз. Это хорошо определяется по 


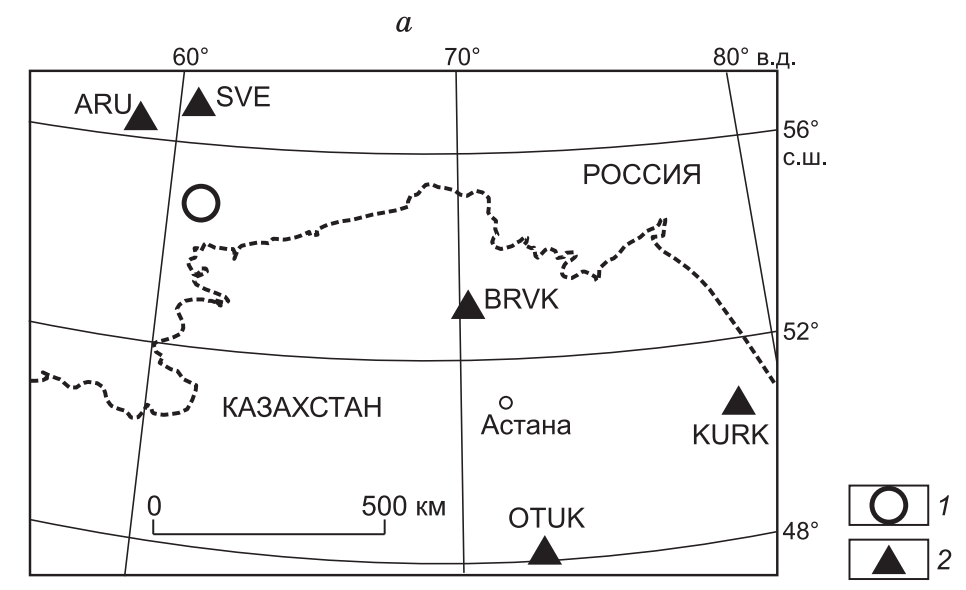

$\Delta$, град.

б

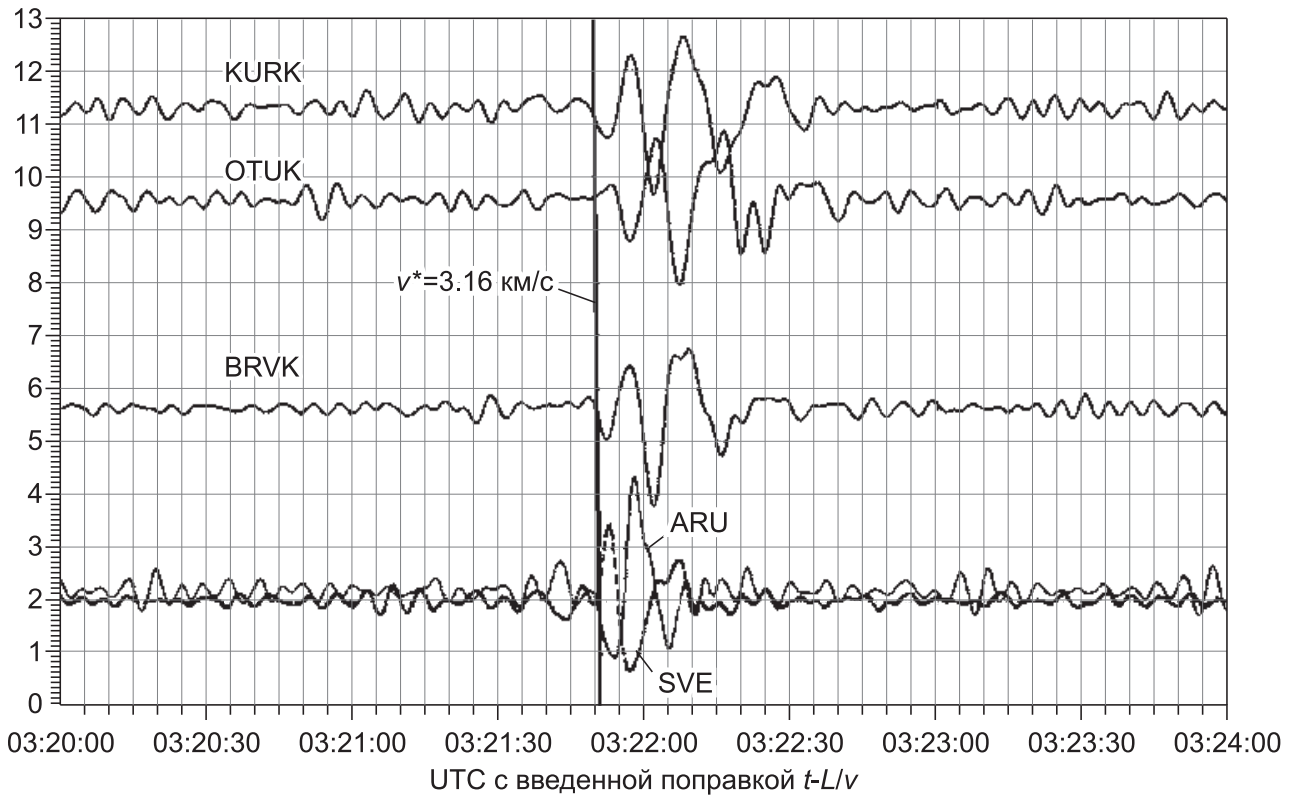

Рис. 4. Схема расположения широкополосных сейсмостанций $(a)$ и сейсмограммы с записью поверхностной волны на вертикальном канале (б).

1 - эпицентр взрыва метороида, 2 - сейсмостанции. $t$ - время, $L-$ эпицентральное удаление (км), $v-$ скорость редукции $\left(3.15\right.$ км/с), $v^{*}$ - кажущаяся скорость поверхностной волны, $\Delta$ - эпицентральное удаление

записям звуковых волн, зарегистрированных в нескольких местах. Взрывы были в начале и в конце участка траектории, находящегося между Т1 и Т2, и они были дискретными.

На рис. 3 приведены годографы звуковой волны для различных высот точки взрыва и ход ее лучей. Видно, что при высоте 25 км зона тени появляется на удалениях 60 км, а при высоте 30 км - около 75 км. В г. Коркино звук пришел через 88 с, при скорости 0.31 км/с это составляет 27.3 км. В пос. Первомайский звук зарегистрирован примерно через 40 с. Это соответствует тому, что первая звуковая волна с высоты 23 км шла около 75 с, а с т. Т2 - около 115 с. До г. Челябинск звуковая волна дошла за 120 - 150 с. В силу того, что скорость звуковых волн у поверхности Земли выше, чем на высоте, и ветер у поверхности дул от места взрыва в сторону города, горизонтальная составляющая в г. Челябинск была значительно больше, чем в поселках, находящихся вблизи траектории движения метеороида. Именно это способствовало тому, что в Челябинске было выбито большое число окон. Для точных расчетов нужно знать скорость ветра на различных высотах и его направление. К сожалению, таких данных у нас нет, но они могут быть получены, например, при анализе изображения дыма из труб, запечатленных на 
Рис. 5. К определению энергии $(Q)$ взрыва метеороида «Челябинск» с использованием зависимости от безразмерной энергии $\left(E_{R} / F\right)$ поверхностной волны, по [Коган, 1975].

видеозаписях. В Миассе, находящемся в $60-65$ км от эпицентра взрыва, звука не слышали (по свидетельствам очевидцев). Это объясняется тем, что при высоте источника 21 км зона тени звуковой волны начинается с расстояния 60 км от эпицентра (см. рис. 3), и тем, что ветер дул от Миасса в сторону Челябинска. Можно примерно оценить размеры области, где можно было услышать звук от взрыва. Этот радиус равен 90 км из т. Т2. А при высоте свечения в т. Т3, равной 68 км, болид могли видеть в области до 800 км от т. Т3 на восток и около 1000 км на запад.

Именно набор звуковых волн из этого участка траектории полета метеороида формировал звуковую волну, зарегистрированную по всему миру (http://www.iris.edu/ $\mathrm{dms} /$ nodes/dmc/specialevents/2013/ 02/19/chelyabinsk-russia-bolide-meteor/\#sthash.7NCko4fy.dpuf).

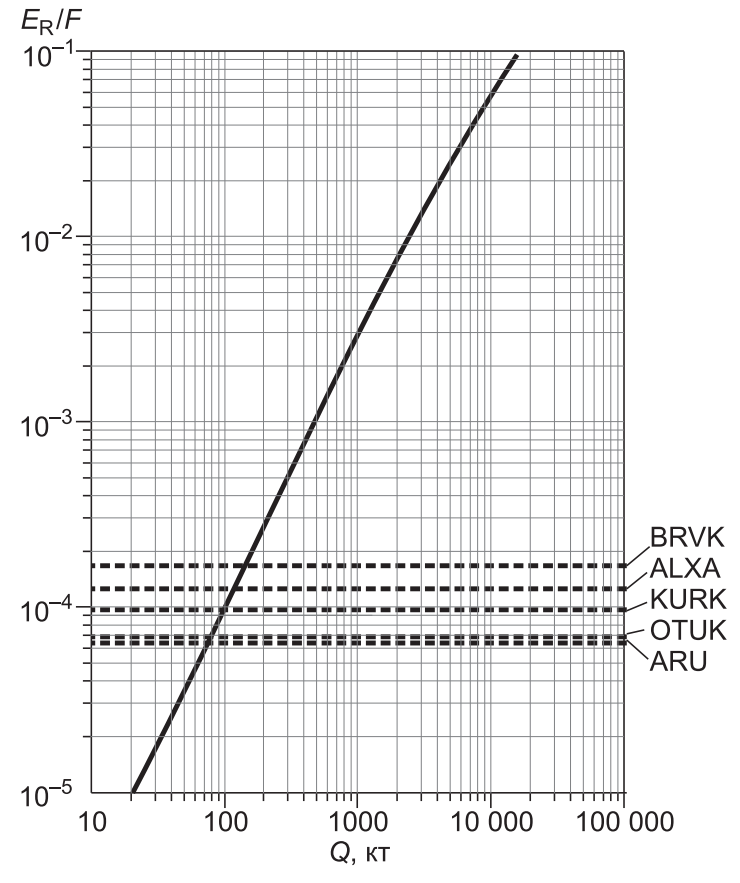

\section{СЕЙСМОЭФФЕКТЫ}

Дождь из осколков метеороида обрушился на район размером не менее 20 км по широте и 40 км по долготе. На сейсмических станциях Арти (ARU) и Свердловск (SVE) зарегистрированы только волны, образовавшиеся в результате падения звуковой волны на земную поверхность, а на более ранних временах выделить надежные вступления каких-либо волн не удается. Можно приближенно оценить максимально возможную сейсмическую энергию землетрясения, вызванного падением осколков метеорного тела. С использованием подходов, принятых в сейсмологии для определения энергии очагов землетрясений, было установлено, что максимально возможная энергия землетрясения не превышает 9-го энергетического класса (иначе на сейсмограммах на фоне микросейсм выделялись бы вступления сейсмических волн).

Записи, полученные на станциях с сейсмологических сетей IRIS GSN/University of California San Diego, Central-Asian Real-Time Earthquake Monitoring Network, Geo Forschungs Zentrum Potsdam, Kazakhstan National Data Center, ГС РАН, ГС СО РАН, являются уникальными (рис. 4). Волны подобного типа образуются при ядерных и термоядерных взрывах в атмосфере [Коган, 1975]. Но это точечные источники, а в случае Челябинского метеороида источник растянут по длине 33.7 км.

По амплитуде поверхностных волн с использованием методики, описанной в [Коган, 1975], была проведена оценка энергии взрыва. В соответствии с указанной методикой использовалась теоретическая зависимость между безразмерной энергией волны Рэлея и энергией взрыва в случае высотного (30 км) источника (рис. 5). По данным с пяти широкополосных станций была рассчитана энергия волны Рэлея $\left(E_{\mathrm{R}}\right)$ и обезразмеривающий параметр $F$. Из рисунка видно, что величина энергии взрыва составляет от 70 до 140 кт, по данным с разных станций, при среднем значении около 100 кт в тротиловом эквиваленте. Необходимо учитывать, что данная оценка энергии выполнена в предположении, что источник точечный.

Для восстановления сейсмической картины необходима точная временная привязка событий, сопровождающих пролет метеороида. На сейсмических записях точность определения времени обычно лучше, чем 1 мс. На видеорегистраторах время выставлялось практически произвольное, за исключением записей, полученных камерами видеонаблюдения на площади Революции и просп. Победы. Если траекторию полета метеороида мы определили верно, то от центра отрезка T1-T2 (район озера рядом с пос. Шумаково) расстояние до камер наблюдения 24 км, а время прихода звуковой волны 77 с. Время в источнике, вычисленное по вступлениям поверхностной волны на ближних станциях, - 3:21:51 UTC (см. рис. 4). Следовательно, по сейсмическим данным, взрыв произошел в 03:20:34 UTC. Первое визуальное наблюдение метеороида в атмосфере было в 3:20:20 UTC (так как от начала свечения до момента взрыва прошло 14 с). Это позволяет считать, что часы на видеорегистраторах на площади Революции и просп. Победы, показывающие такое же время, были точны, и наши расчеты верны с достаточной точностью. 


\section{ЗАКЛЮЧЕНИЕ}

На сейсмограммах зафиксированы волны необычной природы, но число станций слишком мало, чтобы провести их уверенную корреляцию и понять физическое происхождение. Вероятнее всего, метеорное тело двигалось над Новосибирском со сверхзвуковой скоростью в сильноразреженной среде (длина пробега частиц велика в сравнении с его размерами). При описании явлений, происходящих в окрестности тела в такой разреженной среде, обычные методы гидродинамики или аэродинамики оказываются неприменимыми и необходимо использовать кинетическую теорию. При этом весьма важен вопрос о возбуждении волн метеорным телом: оно могло бы возбуждать как звуковые волны, так и ионные плазменные волны. Однако все эти типы волн в условиях, когда длина волны порядка или меньше длины свободного пробега, очень сильно затухают. Поэтому они не могут оказывать существенного влияния на процессы, происходящие вблизи тела [Альперт и др., 1963]. Тем не менее может быть, в момент пролета метеороида «Челябинск» создались условия для распространения такого типа волн по направлению к Земле, что и послужило появлению необычных волн на сейсмограммах. Моделирование процесса может дать ответы на многие вопросы, возникшие в ходе первичной обработки информации.

Данные, полученные во время такого рода явлений, должны быть сохранены для последующего детального анализа. Сейсмические данные с сети ГС СО РАН могут быть доступны не всем исследователям, поэтому мы сформировали базу данных, находящуюся по адресу ftp://ftp.gs.sbras.ru/pub/meteor/. Там же можно найти стоп-кадры видеозаписей с чертежами, использованные нами для определения траектории полета метеороида.

Авторы выражают благодарность А.Г. Яковлеву за помощь в построении годографов звуковых волн при различной высоте источника.

\section{ЛИТЕРАТУРА}

Альперт Я.Л., Гуревич А.В., Питаевский Л.П. Об эффектах, вызываемых искусственным спутником, быстро движущимся в ионосфере или межпланетной среде // УФН, 1963, т. LXXIX, вып. 1, с. 2379.

ГОСТ 44-01. Атмосфера стандартная. Параметры. Введ. 01.07.82. М., Изд-во стандартов, 1981, $179 \mathrm{c}$.

Коган С.Я. Сейсмическая энергия и методы ее определения. М., Наука, 1975, 152 с. 